\title{
Optimized Parameter of Contactless Energy Transmission System Realized by Optimum Energy-Efficiency Product
}

\author{
Jinfeng Liu, Xudong Wang and Meicun Yan \\ School of Electrical \& Electronic Engineering, Harbin University of Science \& \\ Technology, Harbin, China \\ ljf78118@163.com
}

\begin{abstract}
Energy coupling realized by contactless magnetic tank transformer as new approach of rotator excitation in synchronous machine could replace brushes and slip rings of traditional excitation. For new contactless energy transmission (CET) system, its research about energyefficiency quality still remains a low level because application and research of CET isn't comprehensive, especially how to improve transfer power and efficiency isn't enough. According to characteristics of contactless eneroy transmission system, mutual inductance model was used to describe the loosely coupled connection between primary and secondary winding. Then, optimum energy-efficiency product was proposed. We can use this indicator to consider efficiency, system cost, reliability and so on based on maximum output power. Mutual inductance coupling parameter would be optimized through this indicator and optimum design of system energy-efficlency chrorteristic would be realized at minimum cost. Although the input voltage had little inerease, experiment and simulation research proved that system efficiency had Q quit handsome increase based on optimum energy-efficiency product which established mutual inductance coupling parameter. The results of experiment agreed with the results of theor analysis in general and it verified the validity of theory analysis.
\end{abstract}

Keywords: magnetic an transformer; contactless excitation; harmonic compensation; energy-efficiency product

\section{Introduction}

Generally, sliding contact power supply has been used widely to supply power for Excitation systems for synchronous machines and equipments of electric vehicle and electric train in urban transportation. However, this kind of method has some defects such as sliding abrasion, touching spark and carbon deposit. Therefore, new contactless power transfer technology has been invented to improve these detects which based on new technology about induction energy transfer theory. The character by using induction technology is the relative sites of subsystem are stable, and it can realize closed coupled and high transfer efficiency, as in [1] and [2]. As power electronics technology, high-frequency electronic technology and magnetic materials is advancing dramatically and demands of contactless power transfer of electrical equipments for many circumstances are increasing, this new energy transfer 
technology is gradually increasing, as in [3]. The core device of this system to achieve contactless electrical energy transfer is rotary separable magnetic tank transformer, which utilizes the benefit about transfer efficiency won't be influenced by rotate speed when primary or secondary winding of magnetic tank transformer keep rotating state. Primary winding is immovable and secondary winding could rotate being driven by rotor in Figure 1.

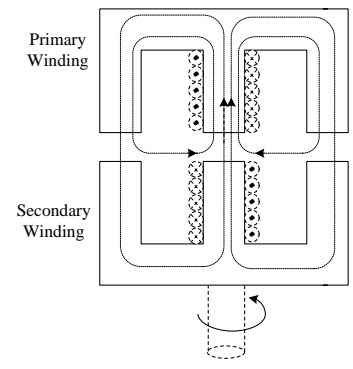

Figure 1. Contactless transformer structure

\section{Transformer Topology Model}

In the power conversion circuit, primary and secondary windings of the transformer model are used to describe the coupled relationship This model Is suitable for the condition of primary and secondary tight coupled modêlin the transformer, primary and secondary voltage meet the ratio of their turns, meanwhile the leakage inductance is usually negligible, as in [4]. Mutual inductance model is another way to describe the coupled between primary and secondary windings of the circuit nodel. Induced yoltage and coupled voltage can be fixed by mutual inductance, coupled voltage reflect the full impact of secondary to primary winding which do not need to separate the mutual inductance and leakage inductance, all above is the main advantage of this model analysis, as in [5]. The essential difference between the contactless transformer and the traditional transformer is the coupled difference between primary and secondary coupled. To the traditional transformer, the coupled coefficient is usually between 0.95 0.98, and close to 1 . Contactless transformer belongs to loosely coupled system, coupled coefficient is all below 0.9 , sometimes even less than 0.1 , as in [6]. This transformer has the xtensive leakage inductance and the core always works in the linear section of the magnetization curve. Considering the advantages of analysis to the mutual inductance model and loosely coupled characteristic of contactless transformer, it's more applicable that use the mutual inductance model to represent the contactless transformer equivalent circuit model. Figure 2 shows the mutual inductance model circuit topology of contactless transformer.

is primary excitation voltage, $\mathrm{L}_{1}$ and $\mathrm{L}_{2}$ are primary inductance and secondary inductance respectively, $M$ is the mutual inductance of the contactless transformer, $R_{1}$ and $R_{2}$ are primary winding and secondary winding resistance respectively, $R_{0}$ is the load resistance. In order to improve system performance and the ability to power transmission, the resonance compensation technology is used in primary winding and secondary winding respectively. $\mathrm{C}_{1}$ and $\mathrm{C}_{2}$ are primary and secondary harmonic compensation capacitance which is using the topologies of the series-series compensation. 


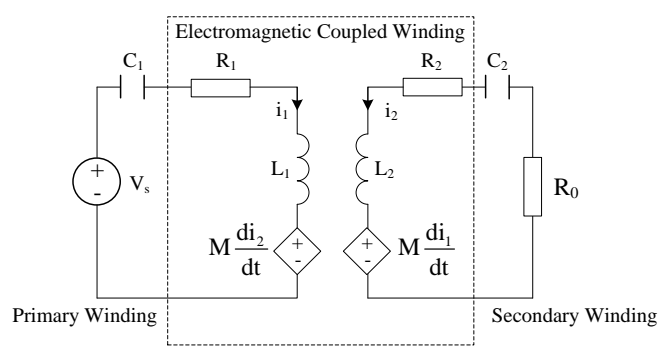

Figure 2. Mutual inductance model of contactless transformer

\section{Parameters Optimized Analysis Based on Optimum Energy-Efficiency Product}

Electromagnet induction coupling structure is the core of contactless energy transmission system and its principle is in accordance with common transformer. Somewhat differently, common transformer is tight coupling model and its magnetio flux is dis ributed mainly over iron core while flux leakage is little because of the high permeability and low reluctance of iron core, so it has tight coupling extent. But the magnetic path of CET belongs to loosely coupling model. Magnetic flux will flow not only in the coil but also in the air magnetic path because the air gap between primary and secondary coil is big, so CET's flux leakage is much and coupling extent is low. The structure of CET has seriously affected power transmission capacity of system and reduced power transmiss on efficiency, as in [7] and [8].

\subsection{Propose Optimum Energy-Efficiency Product}

In order to realize optimum design of system in its totality we should consider not only how to improve efficiency of system as far as possible but also various indicators such as cost, volume, reliability, withstand voltage of implements and so on based on maximum power transmission in the design process of modern electric system. So the assessment function of system is no longer efficiency which is single objective function but multiple objective function which have allowed for above variables. Only realized these objective function can come to the conclusion that the system is optimum. In order to combine with variables of system we need anew assessment indicator because previous efficiency couldn't satisfy requirement, as in (9] and [10].

It's not the most idear result of designer that optimized mutual inductance by taking the CET's maximum transmission power as target in design process of real system. Then a novel synthetical assessment indicator, optimum energy-efficiency product which applied to CET system was proposed that overcame disadvantage of maximum power or efficiency as optimized factor. The output power, efficiency, cost, volume and reliability were considered in this indicalor and it would optimize and analyze mutual inductance coupling parameter of system, thereby realizing overall situation optimum, as in [11].

The definition of energy-efficiency product $\xi$ is:

$$
\xi=\text { efficiency } \times \text { objective function }
$$

The objective function will different for different system. System object will be output power, cost or work reliability of system according to actual requirement.

We can take output power of CET's system as design target. In order to analyze easily and eliminate system output power effect of input voltage, output power must be normalized treatment. Suppose $\varphi$ as the ratio of actual output power to maximum output power, that is, $\varphi$ 
is load ratio of system. We take $\varphi$ as system target and energy-efficiency product will be derived according to the definition:

$$
\xi=\eta \times \varphi
$$

\subsection{Optimized Mutual Inductance Coupling Parameter}

System efficiency is just only $50 \%$ in series\&series harmonic compensation circuit under the maximum output power according to reference [12]. System could realize maximum output power based on optimized mutual inductance coupling parameter at the expense of dramatic decline of efficiency. In order to improve efficiency and guarantee certain transmission power, designer must increase input voltage, raise system cost and decrease reliability. While system efficiency should be improved as far as possible, cost and volume should be reduced and then reliability would be increased in the design process of real system based on certain transmission power.

By means of analysis, expression of transmission efficiency about CET system for series\&series harmonic compensation circuit is:

$$
\eta_{s s}=\frac{P_{s s-o u t}}{P_{s s-i n}}=\frac{\omega^{2} M^{2}}{\omega^{2} M^{2}+R_{o} R_{1}}
$$

Output power when secondary coil resistance is ignored is:

$$
P_{s s-o u t}=\frac{\omega^{2} M^{2} K^{2} R_{o}}{\left(\omega^{2} M^{2}+R_{o} R_{1}\right)^{2}}
$$

In order to derive the relationship between output power and mutual inductance, we could make:

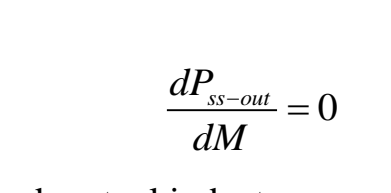

So we would get optimized mutual inductance under the maximum transmission power:

$$
\text { 2 } M_{s s-o p t}=\frac{\sqrt{R_{o} R_{1}}}{\omega}
$$

According to Equation (6) we could know that optimum mutual inductance would be got while system couldn' obtain optimum efficiency in order to realize maximum transmission power. We could get the maximum output power according to expression (4) and (6).

$$
P_{s s-\max }=\frac{V_{s}^{2}}{4 R_{1}}
$$

Load ratio of CET system for SS type on the basis of its definition is:

$$
\varphi_{s s}=\frac{4 \omega^{2} M^{2} R_{o} R_{1}}{\left(\omega^{2} M^{2}+R_{o} \mathrm{R}_{1}\right)^{2}}
$$

Then energy-efficiency product is:

$$
\xi_{s s}=\eta_{s s} \times \varphi_{s s}=\frac{4 \omega^{4} M^{4} R_{o} R_{1}}{\left(\omega^{2} M^{2}+R_{o} R_{1}\right)^{3}}
$$


We could make:

$$
\frac{d \xi_{s s}}{d M}=\frac{d\left(\eta_{s s} \times \varphi_{s s}\right)}{d M}=0
$$

When:

$$
M_{s s-\xi}=\frac{\sqrt{2 R_{o} R_{1}}}{\omega}
$$

Energy-efficiency product would be maximum. Now output power and efficiency is respectively:

$$
\begin{gathered}
P_{s s-\xi}=\frac{2 V_{s}^{2}}{9 R_{1}} \\
\eta_{s s-\xi}=\frac{2}{3}
\end{gathered}
$$

Table 1 shows the contrast of output power and efficiency before and after the new indicator adopted. From this table we could know CET system realized efficiency improvement of $33.3 \%$ at the cost of output power decrease of $111 \%$ under maximum energy-efficiency product indicator.

Table 1. Contrast of output power and efficiency before and after the new indicator adopted

\begin{tabular}{|c|c|c|c|}
\hline & Before $\xi$ adopted & After $\xi$ adopted & Enhancement \\
\hline$P_{\mathrm{o}} / \mathrm{W}$ & $\mathrm{V}_{\mathrm{s}}^{2} / 4 \mathrm{R}_{1}$ & $2 \mathrm{~V}_{\mathrm{s}}^{2} / 9 \mathrm{R}_{1}$ & $-11.1 \%$ \\
\hline$\eta / \%$ & 50 & 66.7 & $33.3 \%$ \\
\hline
\end{tabular}

\section{Experiment and Simulation}

In order to verify aceuracy of optimum energy-efficiency product, we should carry out simulation and experiment analysis.

\subsection{Maximun Transmission Ability Research Based on Energy-Efficiency Product}

Figure 3 show simulation model which is built on the basis of work condition. Mutual inductance parameter of contactless transformer would be assured based on maximum transmission and pptioum energy-efficiency product respectively and then synthetical transmission performance of system would be analyzed.
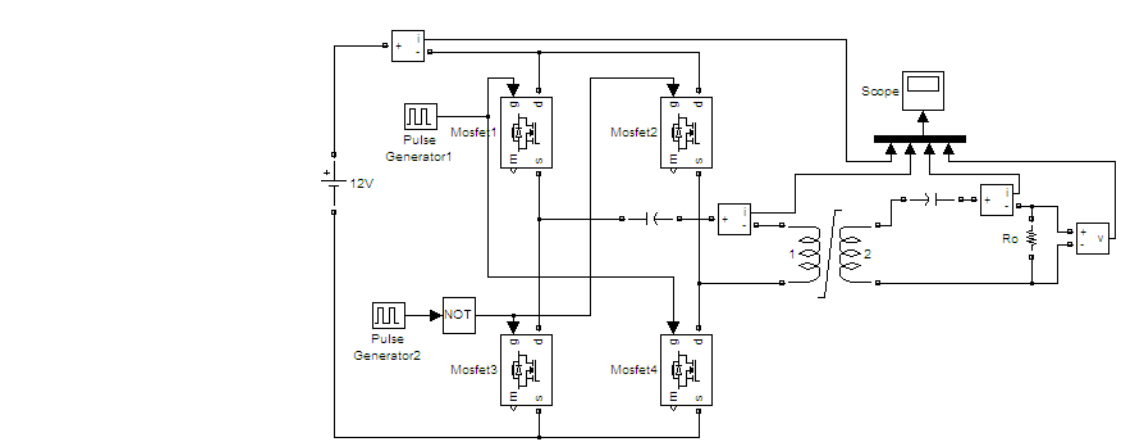

Figure 3. Simulation model of CET system 
We could put parameters which satisfied maximum transmission power and harmonic status into simulation model. Figure 4 shows the simulation waveform. $I_{\mathrm{i}}$ is input current. $\mathrm{I}_{\mathrm{r}}$ is primary current of harmonic circuit. $\mathrm{U}_{\mathrm{o}}$ is load voltage. $\mathrm{I}_{\mathrm{o}}$ is load current.

The phase of load current and voltage is accordance under ideal circumstance from waveform. Then the output power of secondary coil is:

$$
P_{o}=U_{o} I_{o}=12 \times 3.5=42 \mathrm{~W}
$$

The input power of system is:

$$
P_{i}=U_{i} I_{i}=12 \times 7.3=87.6 \mathrm{~W}
$$

The efficiency of system is:

$$
\eta_{p \max }=\frac{P_{o}}{P_{i}}=47.9 \%
$$

The transmission efficiency is more low in the mode of maximum output power.
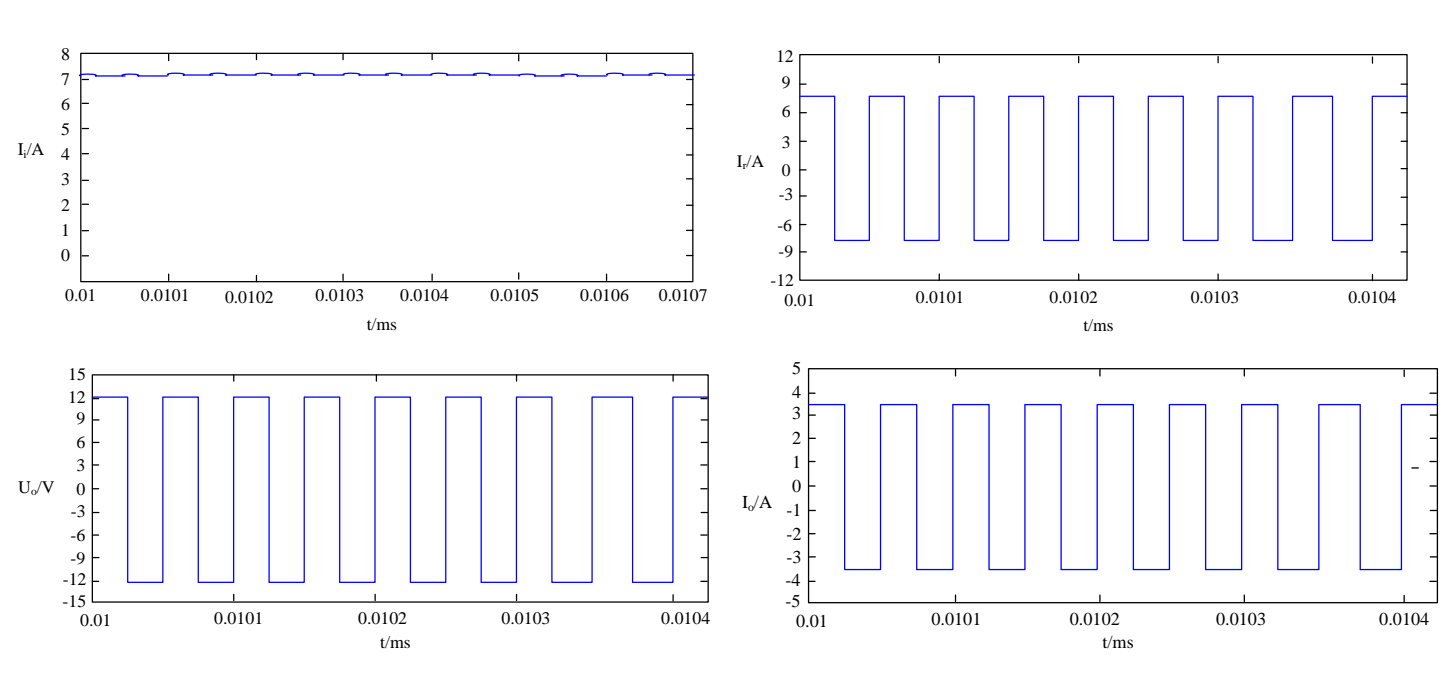

Figure 4. Wa eform in maximum output power condition

Energy-efficiency produet indicator of transmission ability must be considered in order to obtain overall situation optimum. Mutual inductance coupling parameter of contactless transformer could be assured by Equation (11), and then altered the transformer parameter. Figure 5 shows the simulation waveform in optimum energy-efficiency product.
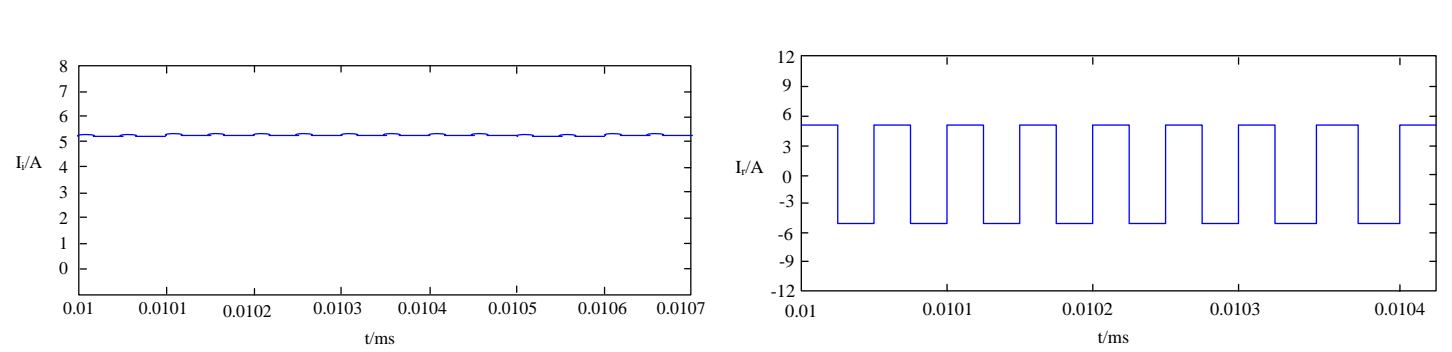

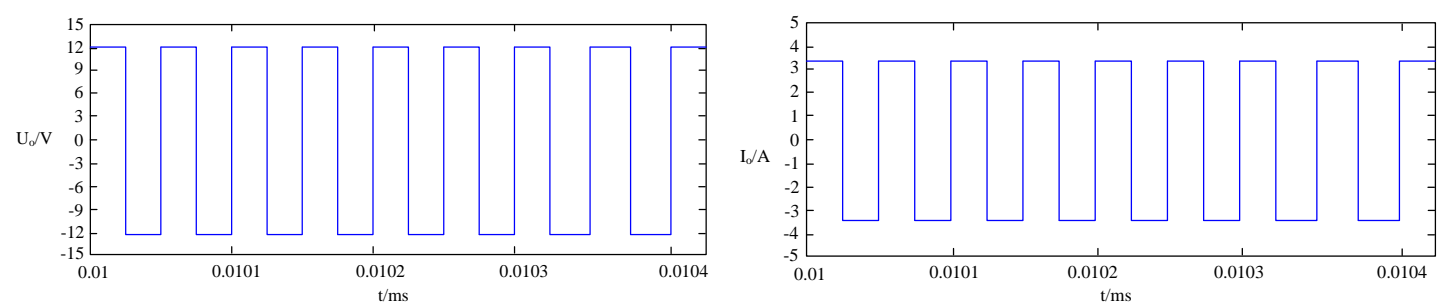

Figure 5. Waveform in optimum energy-efficiency product

The waveform sequence of Figure 4 is in accordance with Figure 5, and the phase of output voltage and current of secondary coil don't shift. So the secondary output power is:

$$
P_{o \xi}=U_{o} I_{o}=12 \times 3.4=40.8 \mathrm{~W}
$$

The input power is:

$$
P_{i \xi}=U_{i} I_{i}=12 \times 5.2=62.4 \mathrm{~W}
$$

The efficiency of system is:

$$
\eta_{\xi \max }=\frac{P_{g}}{P}=65.4 \%
$$

Primary current decreased and transmission effictency improved even though transmission power has been slightly reduced. These are accordance with former theory analysis. It's just because obvious decrease of primary current could reduce not only switch loss of former MOSFET but also heat loss of harmonic cireuit. So the transmission quality of system is increased dramatically and parameters are overall optimized.

\subsection{Experiment Research}

Contactles energy transniss ion system was built in laboratory under the control of LM5035B in order to verify validity of energy-efficiency product. Then the energy-efficiency parameters were obtained ás shown in Table 2.

\section{Table 2. Contrast of energy-efficiency parameters}

\begin{tabular}{|l|l|l|l|}
\hline \multirow{3}{*}{ Theory Value } & Parameter & Before $\xi$ adopted & After $\xi$ adopted \\
\hline \multirow{3}{*}{ Experiment Value } & $I_{i} / \mathrm{A}$ & 7.3 & 5.2 \\
\cline { 3 - 5 } & $\eta / \%$ & 47.9 & 65.4 \\
\cline { 2 - 5 } & $P_{o} / \mathrm{W}$ & 42 & 40.8 \\
\cline { 2 - 4 } & $I_{i} / \mathrm{A}$ & 7.9 & 5.1 \\
\cline { 2 - 4 } & $\eta^{\prime} / \%$ & 45.6 & 68.6 \\
\cline { 2 - 4 } & $P_{o} / \mathrm{W}$ & 43.2 & 42 \\
\hline
\end{tabular}

The experiment waveform of input and output current through $1 \Omega$ resistance in maximum output power and optimum energy-efficiency product respectively are shown in Figure 6. 

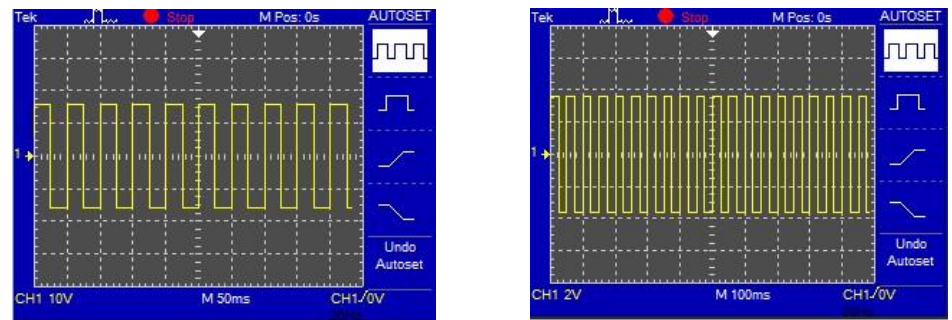

(a)Maximum output power
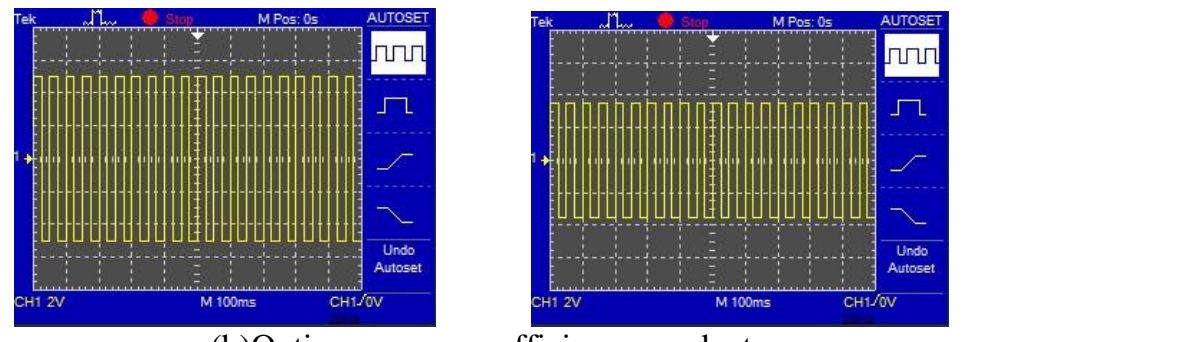

(b)Optimum energy-efficiency, product

Figure 6. Experimen wayeform

\section{Conclusions}

Performance analysis was more complex to contactless energy transmission system which had series\&series harmonic compensation So this paper froposed optimum energy-efficiency product indicator which could optimize the mutual inductance parameter, realize energy transmission with high efficiency and power, reduce the investment cost, improve security of system. Then the transmission performance fCET system achieved optimum operating point.

\section{Acknowledgements}

This work is suppoted by National Natural Science Foundation (51177031). My deepest gratitude goes first and foremost to Professor Wang Xudong, my supervisor, for his constant encouragement and guidance. He has walked me through all the stages of the writing of this thesis. Without his consistent and illuminating instruction, this thesis could not have reached its present form. Second, I would like to express my heartfelt gratitude to Professor Yang Fang, who led me into the world of Power electronic. Last my thanks wouldigo to my beloved family for their loving considerations and great confidence in me all through these years. I also owe my sincere gratitude to my friends who gave me their help and time in helping me work out my problems during the difficult course of the thesis.

\section{References}

[1. Akuo, "Design theory of Wireless Power System Based on Magnetically Coupled Resonators", IEEE International Conference on wireless Information Technology and System, (2010) May 20-22: Honolulu, United States.

[2] M. Franco, C. Alessandra and D. Marco, "Harmonic Balance Design of Wireless Resonant-type power transfer links", IEEE International Microwave Workshop Series on Innovative Wireless Power Transmission, (2012) June12-14: Kyoto, Japan.

[3] L. Ying and J. Vikram, "Design of retrodirective antenna arrays for short-range wireless power transmission", IEEE Transactions on Antennas and Propagation, vol. 4, no. 60, (2002).

[4] G. Kamil A, T. Ryan and W. Chuck, "Loosely coupled wireless power transfer: Physics, circuits, standards", IEEE International Microwave Workshop Series on Innovative Wireless Power Transmission, (2012) May 810: Kyoto, Japan. 
[5] Z. Wei, C. Qianhong and S. C. Wong, "Reluctance Circuit and Optimization of a Novel Contactless Transformer", Proceedings of the CSEE, vol. 10, no. 30, (2010).

[6] C. Chin-Jung, C. Tah-Hsiung and L. Chih-Lung, "A Study of Loosely Coils for wireless power transfer", IEEE Transactions on Circuits and System, vol. 8, no. 57, (2010).

[7] F. Kyriaki and F. Brian W, "Wireless power transfer in loosely coupled links: Coil misalignment model", IEEE Transactions on Magnetics, vol. 5, no. 47, (2011).

[8] A. Ikuo and K. Takuya, "A Simple design of resonator-coupled wireless power transfer", IEEJ Transactions on Electronics, Information and System, vol. 2, no. 130, (2010).

[9] K. Eun-Soo, S. Hwan-Kook and K. Joo-Hun, "Efficiency characteristics of a half-bridge series resonant converter for the contactless power supply", IEEE Applied Power Electronics Conference and Exposition, (2008) February 15-18: Autin, United States.

[10] H. Sarnago, O. Lucia and A. Mediano, "High-efficiency high-power density series resonant inverter based on a multi-Mosfet cell implementation", IEEE Applied Power Electronics Conference and Exposition, (2013) March 20-22: Long Beach, United States.

[11] S. Yue, X. Chenyang, D. Xin and S. Yugang, "Efficiency Analysis and Parameter Optimization of CPT System", Journal of Southwest Jiaotong University, vol. 6, no. 12, (2010).

[12] B. Hamed and F. Kourda, "Self-oscillating half bridge series resonant converter at migh efficiency", Proceedings of the Mediterranean Electrotechnical Conference, (2012) March 5-7: Yasmine Hammamet, Tunisia.

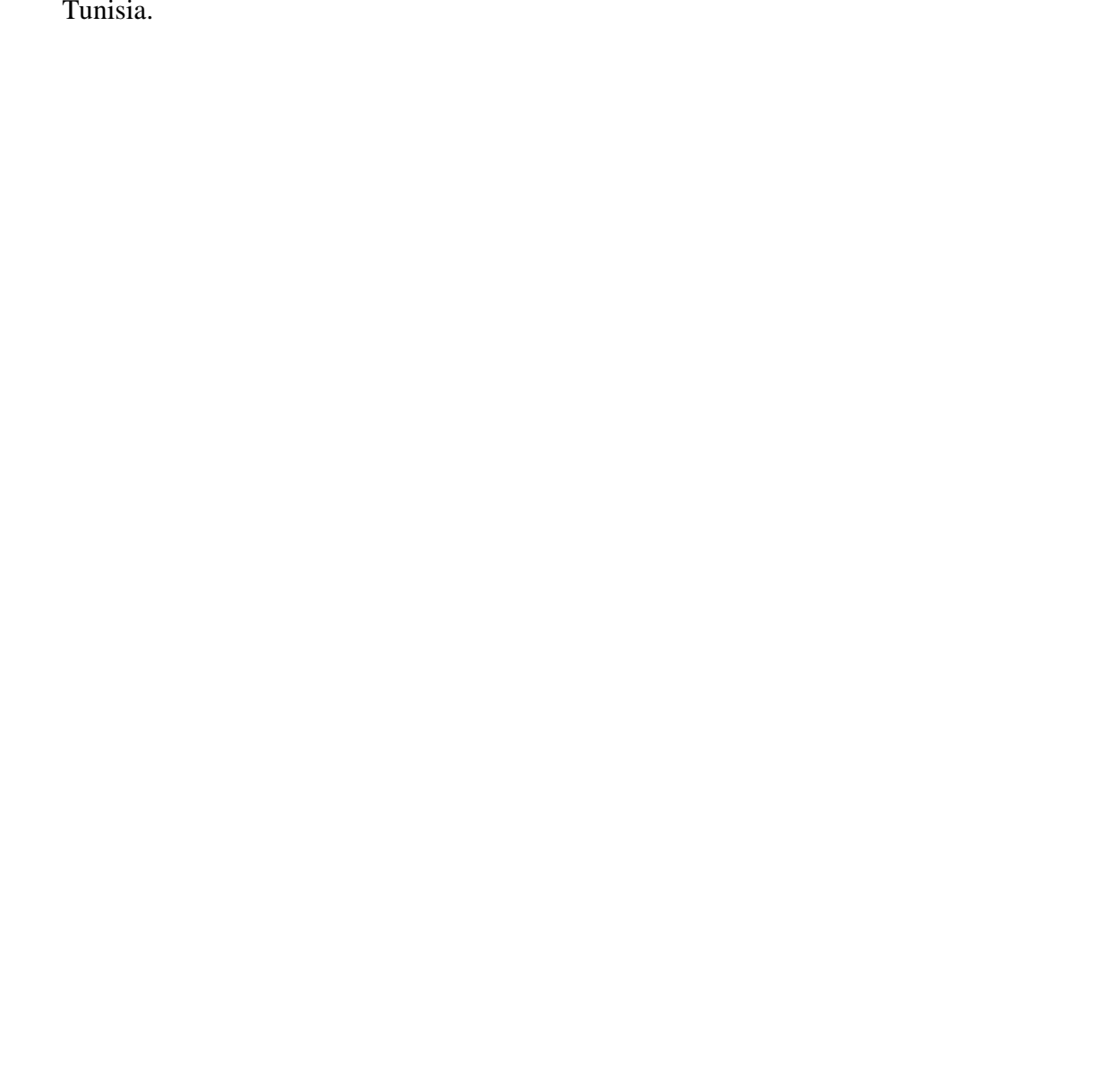


International Journal of Hybrid Information Technology

Vol.7, No.2 (2014)

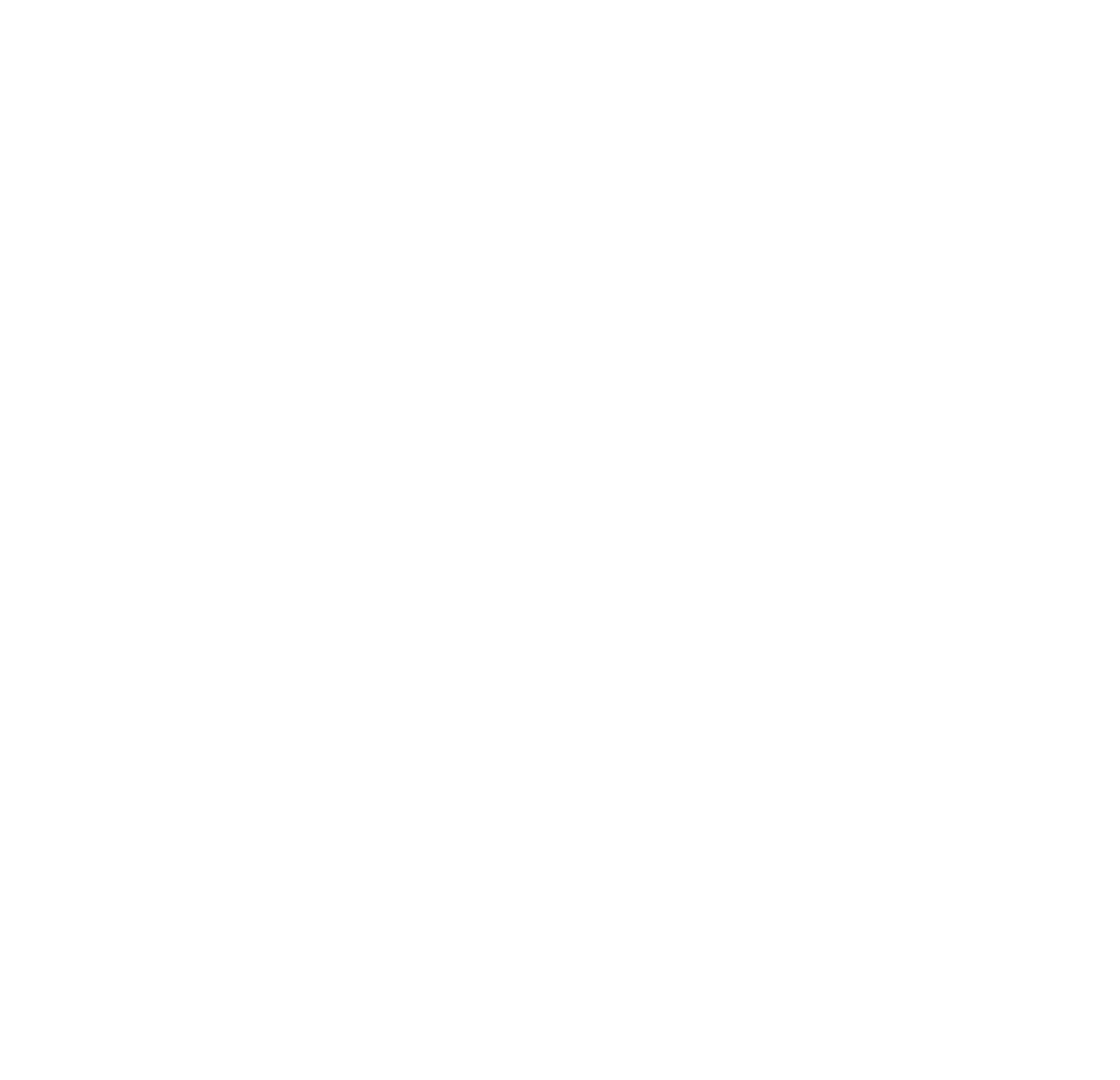

